
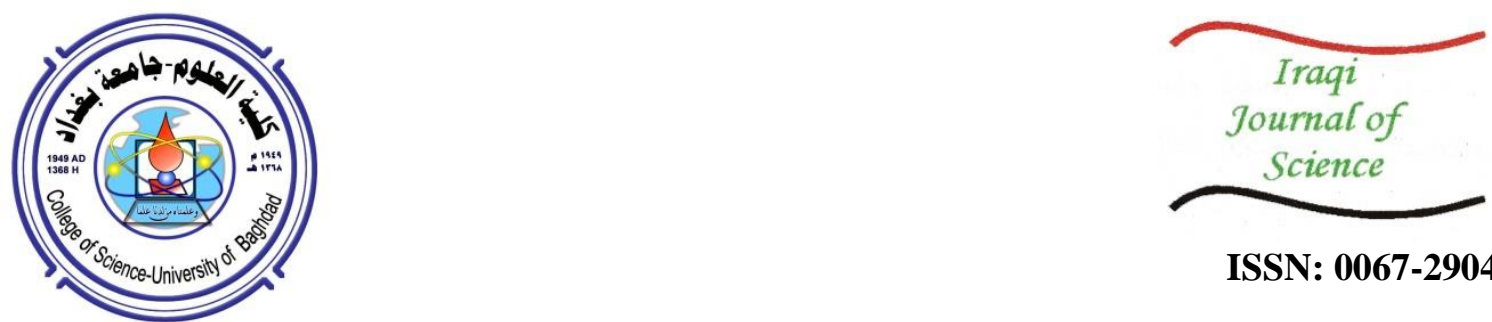

ISSN: 0067-2904

\title{
Irradiation Effects on The Sensitivity of ZnO Thin Films Synthesized on Glass Substrate by Sol-gel Method
}

\author{
Yasir Yahya Kasim, Ghazwan Ghazi Ali*, Marwan Hafeedh Younus \\ Department of Physics, College of Education for Pure Science, Mosul University, Mosul, Iraq
}

Received: 15/12/2019

Accepted: 1/6/2020

\begin{abstract}
This work investigates the structural, optical, and surface properties of $\mathrm{ZnO}$ thin films prepared by sol-gel method. The effect on waveguide sensor was examined at different irradiation durations of alpha particles. The X-ray diffraction (XRD) measurements revealed that the crystalline phase of $\mathrm{ZnO}$ thin films does not change after irradiation and showed a hexagonal structure of wurtzite type with an orientation toward (002). Moreover, $\mathrm{ZnO}$ thin films absorbance was increased with increasing irradiation time, whereas the transmittance was decreased. Additionally, increasing the irradiation time of alpha particles caused an increase in the extinction coefficient and the imaginary part, while the optical energy gap of the $\mathrm{ZnO}$ samples was decreased. Finally, the maximum value of sensitivity was $42 \%$, found at 6 min of irradiation duration.
\end{abstract}

Keywords: Alpha particles, $\mathrm{ZnO}$ thin films, Sol-gel.

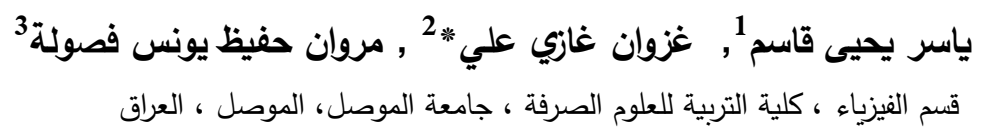

Sol-gel أثير التشعيع على استجابة الاغثية الرقيقة ZnO المرسبة على ارضية زجاجية بطريقة

الخلاصة

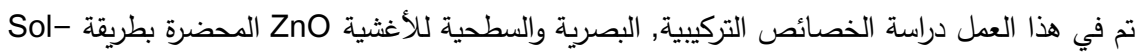

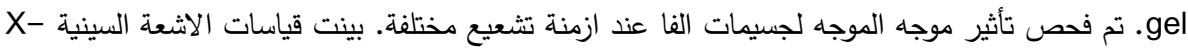

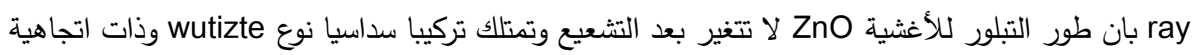

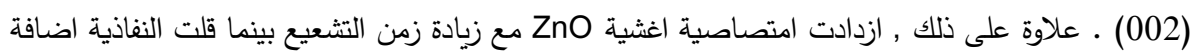

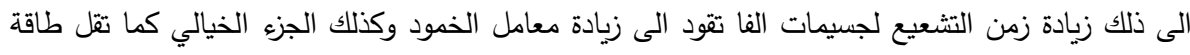

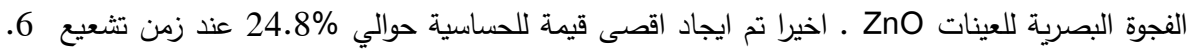

$\min$

$$
\text { الكلمات المفتاحية: جسيمات الفا , اوكسيد الزنك , , Sol-gel }
$$

\section{Introduction}

Zinc oxide $(\mathrm{ZnO})$ thin films have been extensively studied due to the high optical and electrical properties, which can be employed in different applications, such as solar cells and sensors $[1,2]$. Moreover, $\mathrm{ZnO}$ has attracted considerable attention as a promising candidate for inexpensive, light weighted, and light-absorbing mediums [3,4]. ZnO thin films can be deposited in several methods such as the evaporation method [5,6], metal organic chemical vapor deposition (MOCVD) [7], 
sputtering [8] and spray pyrolysis [9]. Furthermore, $\mathrm{ZnO}$ thin films have been used as sensing materials of reactions of chemicals and gases [10]. The researchers attempted to improve the sensitivity by different methods, such as the alloying, doping, annealing, and irradiation, which increase the sensitivity of $\mathrm{ZnO}$ for detecting [11,12]. On the other hand, the irradiation technique has been recently used to enhance the properties of $\mathrm{ZnO}$ thin films [13,14,15]. The interaction between the radiation and matter, especially alpha particles, changes the optical and electrical characteristics of the materials $[16,17,18]$. Alpha irradiation plays a key role to enhance the sensitivity of the $\mathrm{ZnO}$ thin film sensor, deposited on glass substrate by sol-gel method, to detect glucose solution.

\section{Experimental part}

Sol-gel method has attracted the attention of many researchers and used in the deposition of various types of oxides due to essential for the growth along the preferred orientation and give uniform surface. The $\mathrm{ZnO}$ thin films were prepared using sol-gel method. Zinc hydroxide acetate ( $\mathrm{Zn}$ $(\mathrm{CH} 3 \mathrm{COO})_{2} \mathrm{HO}$ with a weight of $0.2195 \mathrm{~g}$ was dissolved in a mixture of $10 \mathrm{ml}$ ethanol with and 90 $\mathrm{ml}$ deionized water in room temperature. The mixture was kept under constant stirring for $20 \mathrm{~min}$ using magnetic stirrer to completely dissolve. To enhance the homogeneity, $0.5 \mathrm{~g}$ polyvinylpyrrolidone (PVP) was added to the mixture which was then kept under constant stirring for 24 hours. Afterwards, the glass substrates were washed with distilled water and methanol and cleaned with ultrasonic waves, respectively. Finally, the $\mathrm{ZnO}$ thin films were deposited on 320nm-thick glass substrates and exposed to alpha particles emitted from Am-241 source with energy of $3 \mathrm{MeV}$ to increase its sensitivity during the glucose detection process. The energy of alpha particles was calculated based on the following equation:

$$
E_{\alpha=} E_{o}\left[1-\frac{x}{R}\right]^{2 / 3}
$$

where $x$ represents the distance between sample and irradiated source, $E_{o}$ is the maximum energy of alpha particles at $\mathrm{x}=0$ (equal to $5.485 \mathrm{MeV}$ ), and $\mathrm{R}$ is the range of alpha particles in the space and can be obtained by SRIM program [19].

\section{Setup of glucose sensing test}

Figure-1 illustrates the experimental setup of the glucose sensing test applied in the present study . The laser source emitted at $650 \mathrm{~nm}$ wavelength and a high sensitive avalanche photo detector (EPPT2000 ) with a range of $600 \mathrm{~nm}$ to $1200 \mathrm{~nm}$ was used. The waveguide, coated with different $\mathrm{ZnO}$ thin films, was used as a sensor and placed between the source and the detector of glucose solution. The irradiated waveguide sensor coated with $\mathrm{ZnO}$ thin films was exposed to different concentration of glucose solution. The light emitted from the laser source was passing through the surface of the irradiated waveguide during glucose detection. Then, the absorption of the power of light detected by the photo detector was increased, leading finally to increase the sensitivity of the sensors.

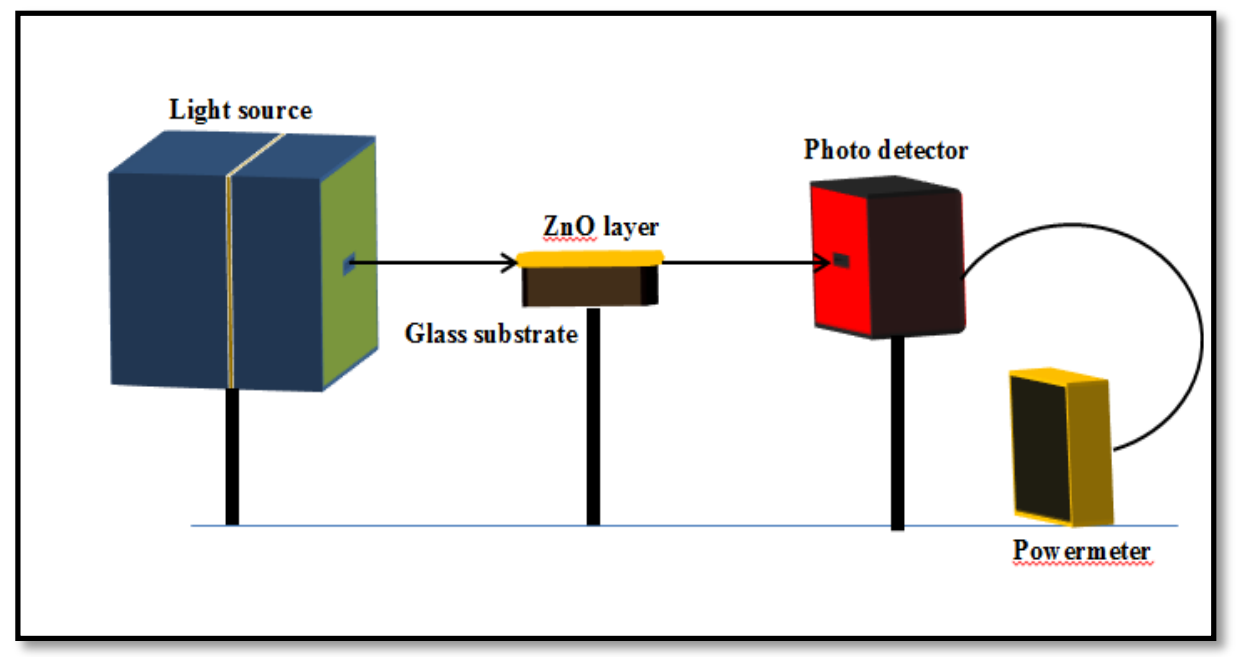

Figure 1-Sensing experimental setup 


\section{Results and Discussion}

\section{$\mathrm{X}$-ray diffraction (XRD) measurement}

The XRD patterns of $\mathrm{ZnO}$ films, with different thickness, deposited on the glass substrate before and after alpha irradiation are presented in Figure- 2. Alpha particles of $3 \mathrm{MeV}$ emitted from Am-241 source were irradiated on the $\mathrm{ZnO}$ at different time periods of 2, 4 and $6 \mathrm{~min}$. It can be seen from Figure- 2 that the patterns of XRD indicate a hexagonal structure and well $\mathrm{C}$-axis orientation after alpha irradiation [20]. Moreover, the XRD analysis shows a strong peak of $\mathrm{ZnO}(002)$ at $2 \theta=34.24$, while the other peaks are found toward the plane orientations (100), (101), (102) and (110) at $2 \theta$ $=31.73^{\circ}, 2 \theta=36.23^{\circ}, 2 \theta=48.34^{\circ}$ and $2 \theta=57.32^{\circ}$ respectively. Furthermore, the XRD results confirmed that the peaks intensity increases with increasing irradiation time, which could be due to the breaking of bonds on the surface of $\mathrm{ZnO}$ thin film. The XRD analysis also revealed that the irradiated $\mathrm{ZnO}$ films were still in the crystalline phase and in good homogeneity. The grain size of the deposited $\mathrm{ZnO}$ thin films can be calculated using Scherrer equation 1 [21] :

$$
D=\frac{K \lambda}{\beta \cos \theta}
$$

where $\mathrm{D}$ is the grain size, $K$ is a constant which is equal to $0.89, \lambda$ is the wavelength of XRD $\quad(\mathrm{Cu}$ $K_{\alpha}$ ) which is $1.54178 \mathrm{~A}^{\circ}$, and $\beta$ is the full width at half maximum. It can be observed that the grain size increases with the increase in irradiation time, due to the defect of clusters of samples that were formed after irradiation, as well as the interface in the localization of states on the $\mathrm{ZnO}$ surface, as shown in Table-1.

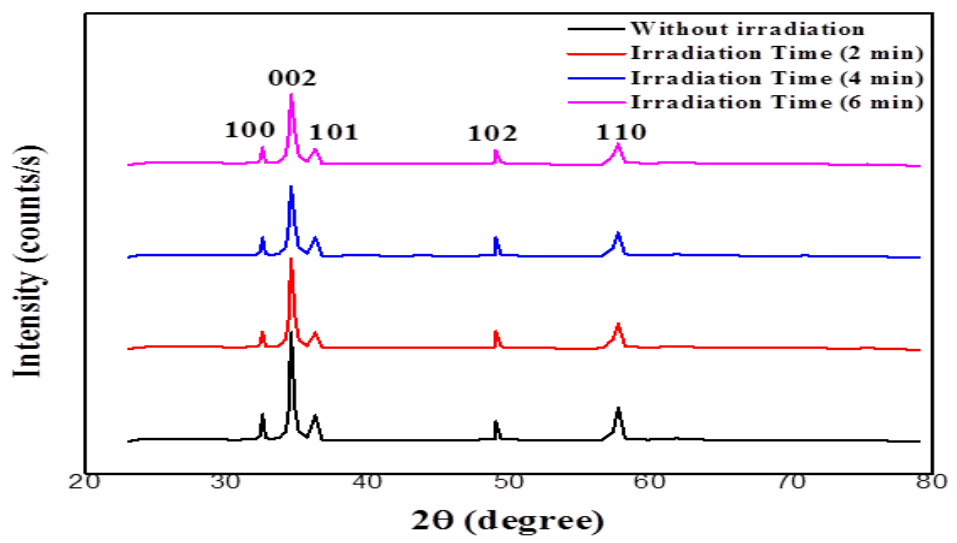

Figure 2-XRD patterns of $\mathrm{ZnO}$ thin films before and after irradiation at time periods of $2 \mathrm{~min}, 4 \mathrm{~min}$, and $6 \mathrm{~min}$.

Table 1- $\mathrm{ZnO}$ grain size and FWHM as a function of irradiation time

\begin{tabular}{ccc}
\hline \hline Irradiation time (min) & Grain Size (nm) & FWHM (radian) \\
\hline \hline 0 & 18.34 & 0.52 \\
\hline 2 & 22.67 & 0.45 \\
\hline 4 & 28.65 & 0.43 \\
\hline 6 & 32.22 & 0.39 \\
\hline
\end{tabular}

\section{Optical properties}

The optical properties before and after irradiation of $\mathrm{ZnO}$ thin films were studied. Figure- 3 shows the absorption spectra as a function of the wavelength. The results indicate that the absorbance of $\mathrm{ZnO}$ thin films was increased for all irradiation times. This might be due to the breaking of bonds on the $\mathrm{ZnO}$ surface after alpha irradiation, which leads to increase the absorbance mechanisms. Increasing of irradiation time leads to formation defects. These defects are considered as an interesting factor in 
photonic devices as they play important roles in the optical properties of a material by introducing absorption bands or color centers [22]. The $\mathrm{ZnO}$ thin films were still in crystalline phase and did not change in crystal structure after irradiation . Furthermore, the diffraction peak of the $\mathrm{ZnO}$ thin film was oriented along the C-axis (002) after irradiation. Figure- 4 shows the results of transmittance against wavelength of the samples. The transmittance of $\mathrm{ZnO}$ thin films was decreased for all irradiation times in comparison with the non-irradiated $\mathrm{ZnO}$ samples. This is related to defects on the rough surface of $\mathrm{ZnO}$ after alpha irradiation, leading to a noticeable decrease in the transmittance [23].

Figure-5 illustrates the absorption coefficient of non-irradiated and irradiated $\mathrm{ZnO}$ thin films as functions of wavelength. The absorption coefficient increases as the irradiation time increases for all the samples. This could be due to the change in the crystal structure of $\mathrm{ZnO}$ after irradiation [24]. Moreover, all the irradiated $\mathrm{ZnO}$ samples exhibited high magnitudes of the absorption coefficient, which could lead to the direct transition band gap of $\mathrm{ZnO}$. These results are consistent with those reported by Muhammad [25]. Figure- 6 shows the relationship between $(\alpha h v)^{2}$ and photon energy $(\mathrm{h} v)$ of non-irradiated and irradiated $\mathrm{ZnO}$ thin films . The energy gap $\left(\mathrm{E}_{\mathrm{g}}\right)$ can be calculated via Tauc formula:

$$
\alpha h v=B(h v-E g)^{r}
$$

where $\mathrm{B}$ is constant, $\alpha$ is the absorption coefficient, ho is photon energy, and $\mathrm{r}$ takes the value of $1 / 2$ at direct transition and 2 at indirect transition. The results show that the optical energy gap decreases with irradiation time, with values of 3.26, 3.21, 3.16, 3.1 eV for irradiation times of 2, 4 and $6 \mathrm{~min}$, respectively. This behavior can be justified by generating extra energy states after irradiation as well as interface band transition at localized states in the energy gap. The values of calculated energy gap are in agreement with those reported by Khan [26]. The results of optical properties after irradiation are attributed to the defects in $\mathrm{ZnO}$ thin films. Most of these defects are created by the localization of oxygen vacancies and change of electronic structure [27]. Furthermore, ionized radiation through thin films causes the loss of most of the energy, due to non-elastic collision of radiation with electrons on $\mathrm{ZnO}$ surface or losing of energy due to elastic collision with atomic nucleation of material [28].

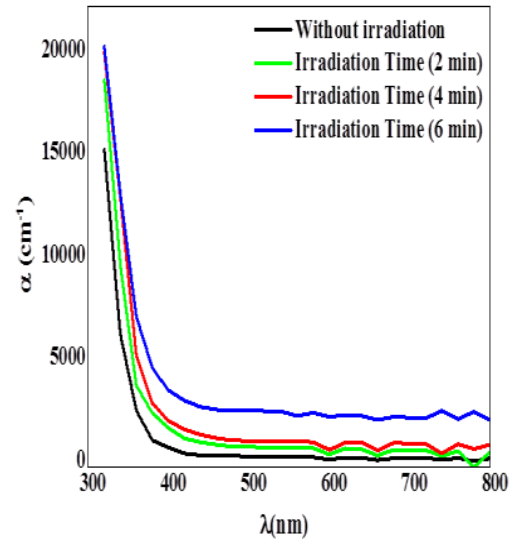

Figure 5-Absorption coefficient against wavelength for different irradiation times.

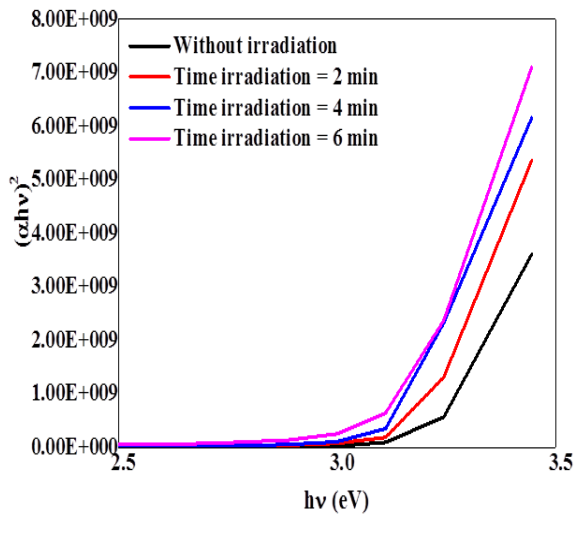

Figure 6-The $(\alpha h v)^{2}$ against hv for different irradiation times

In addition, the extinction coefficient of $\mathrm{ZnO}$ thin films, which includes both the real and imaginary parts of dielectric constant, was studied in the wavelengths range of 300-800 $\mathrm{nm}$. The extinction coefficient $\left(\mathrm{k}_{\mathrm{o}}\right)$, real part $\left(\varepsilon_{\mathrm{r}}\right)$, and imaginary part $\left(\varepsilon_{\mathrm{i}}\right)$ was decreased with increasing wavelength for all samples. The values of extinction coefficient and imaginary part of irradiated samples were larger than those of the non-irradiated samples . Moreover, the values of the real part were smaller than those before irradiation, as shown Figure-9 [29, 30]. 


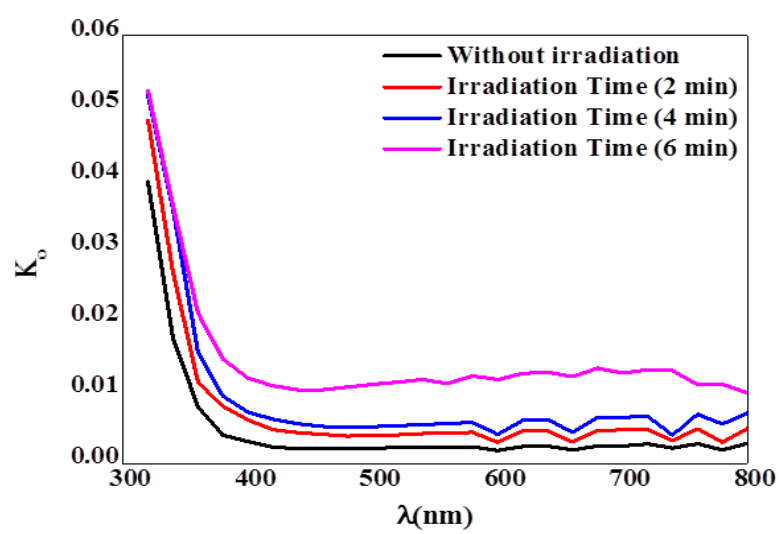

Figure 7- Extinction coefficient versus hv for different irradiation times

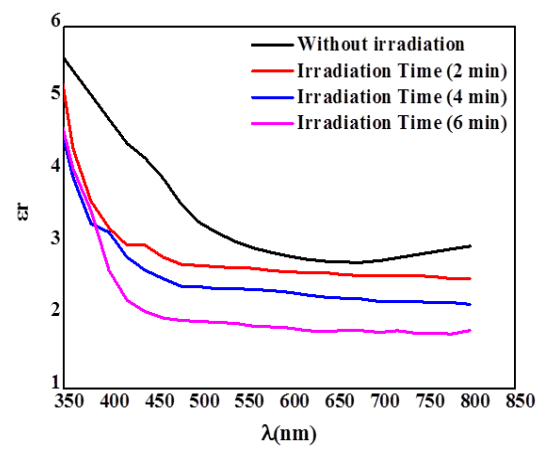

Figure 8- Real part $\varepsilon_{r}$ versus hv for different irradiation times.

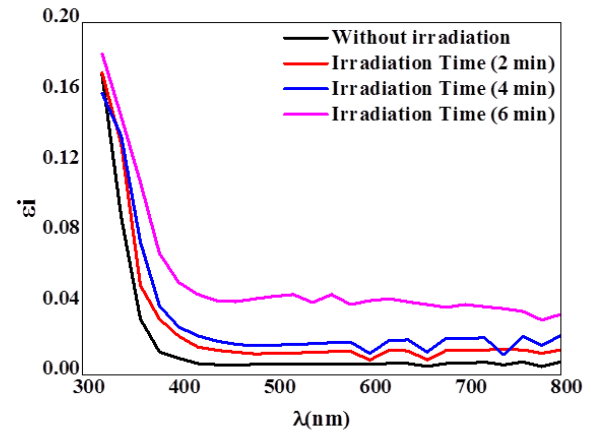

Figure 9- Imaginary part $\varepsilon_{i}$ versus hv for different irradiation times

\section{Scanning Electron Microscopy (SEM)}

Figure-10 shows the SEM images of non-irradiated and irradiated $\mathrm{ZnO}$ thin films for different times (2, 4, and $6 \mathrm{~min})$. The images reveal that the grain size evidently increases when the irradiation time is increased [31]. This could be due to the defects formed on the $\mathrm{ZnO}$ surface caused by alpha particles, which lead to the formation of large-sized nuclei, especially at the longer irradiation time. Therefore, this can open the possibility for manipulating the crystallinity, shape, and size of the grains via controlling irradiation time [32]. 

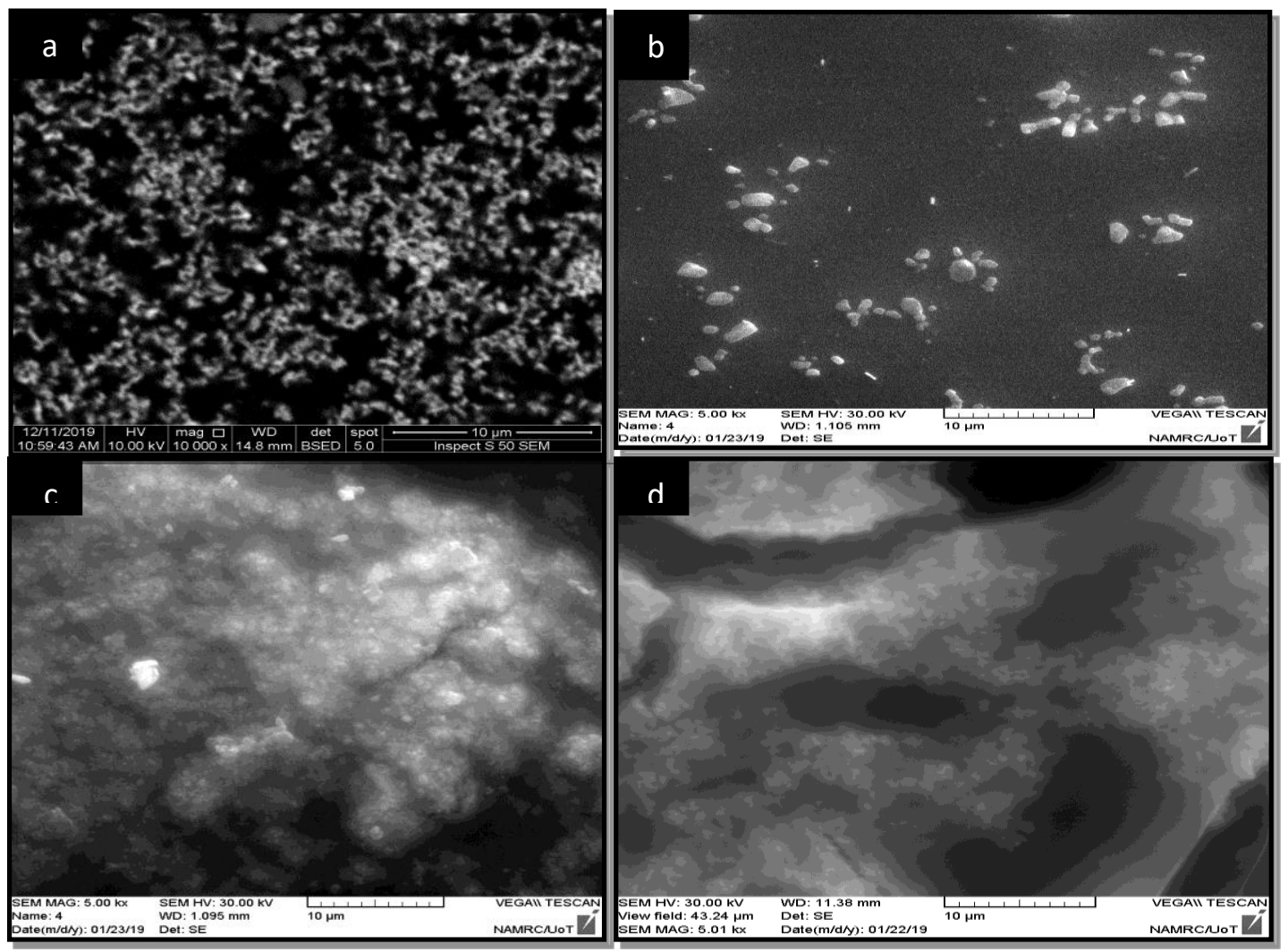

Figure 10- SEM images of $\mathrm{ZnO}$ thin films before and after irradiation time (a) before irradiation, (b) irradiation time $2 \mathrm{~min}$, (c) irradiation time $4 \mathrm{~min}$, and (d) irradiation time $6 \mathrm{~min}$.

\section{Waveguide sensor for glucose detection}

The prepared samples were used in the detection of various concentrations of glucose solution. Figure- 11 shows the normalized power of the light passing through the $\mathrm{ZnO}$ surface versus glucose concentration, before and after irradiation. As can be observed, the normalize power was increased as the time irradiation increased during the detection processes. This could be due to defects, such as those in color centers, on the $\mathrm{ZnO}$ surface after irradiation which lead to increase the absorbance process . Additionally, the response of $\mathrm{ZnO}$ to glucose solution, for all irradiation times, was found to be linear. The gradients of the lines were employed to give the sensitivity of $\mathrm{ZnO}$. The results showed that the sensitivity of the $\mathrm{ZnO}$ for glucose detection increases as the irradiation time is increased. The maximum sensitivity of the $\mathrm{ZnO}$ is approximately $42 \%$ at $6 \mathrm{~min}$ irradiation time, whereas the minimum sensitivity is approximately $25 \%$ and $14 \%$ at 4 and $2 \mathrm{~min}$, respectively. Figure- 12 shows the linear fitting of the $\mathrm{ZnO}$ sensitivity with various $\mathrm{ZnO}$ thicknesses. The $\mathrm{R}$-square value for the linear line fitting is 0.98221 , which indicates a good linearity. The proposed $\mathrm{ZnO}$ sensor can be implemented for glucose detection due to the good line fitting characteristics.

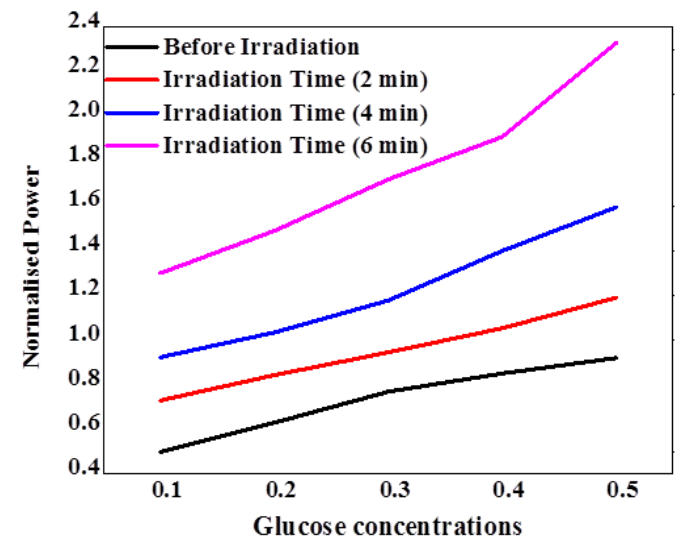

Figure 11-Normalized power versus glucose concentration of $\mathrm{ZnO}$ after Alpha irradiation

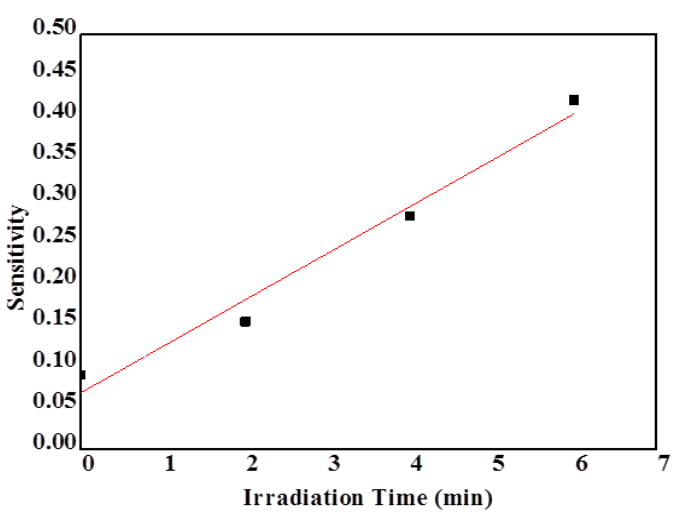

Figure 12-Sensitivity percentage versus irradiation time of $\mathrm{ZnO}$ waveguide sensors 


\section{Conclusions}

Waveguide sensor was designed and fabricated by depositing $\mathrm{ZnO}$ thin films on glass substrates using sol-gel method and then irradiated by alpha particles. Structural, optical, and morphological properties of the $\mathrm{ZnO}$ thin films were examined and analyzed. The $\mathrm{X}$-ray diffraction patterns revealed a slight shift, while the crystalline size increases, with increasing irradiation time. Moreover, the band gap slightly decreases after irradiation. Furthermore, the waveguide sensor showed an improved sensitivity to detect glucose solution with increasing irradiation time. The higher value of sensitivity was $42 \% \mathrm{~dB} / \mathrm{con}$ at irradiation time of $6 \mathrm{~min}$, while the value before irradiation was found to be $9.4 \%$ $\mathrm{dB} /$ con. The irradiation process increased the absorbance of the sensor, which in turn increased the sensitivity of waveguide sensor. This may be used to monitor liquid leakages in different fields, such as fuel stations, wells, and oil pipes.

\section{References}

1. Khan M., Rabia Q., Norah A. and Hayat S. 2017. Characterizations of multilayer ZnO thin films deposited by sol-gel spin coating technique, Results in Physics, 7: 651-655.

2. Mursal A., Irhamni J., Bukhari K. and Zulkarnain J. 2018. Structural and Optical Properties of Zinc Oxide $(\mathrm{ZnO})$ based Thin Films Deposited by Sol-Gel Spin Coating Method. J. Phys.: Conf. Ser.1116

3. Nel J., Ahmed, M., Ahmed M. and Meyer W. 2019. Processing of and electrical properties of $\mathrm{ZnO}$ thin films and nanorods for sensor applications, Proc. SPIE. 11043, Fifth Conference on Sensors

4. Ashraf R., Riaz S. and Naseem S. 2013. Synthesis and characterization of $\mathrm{ZnO}$ nanoparticles ". Advance in nano, Seoul Korea .4(2): 213-219

5. Chávez-Urbiola, I. R., et al. 2019. Development and characterization of photodiode $\mathrm{n}-\mathrm{ZnO} / \mathrm{p}-\mathrm{Si}$ by Radio Frecuency Sputtering, a sensor with low voltage operation and its response to visible and UV light. Thin Solid Films, 669: 364-370.

6. Ghazwan Gh. Ali, Abdul Kahliq A. Sulaiman, and Ivan B.Karomi . 2018. The Effect of the ZnO Thickness Layer on the Porous Silicon Properties Deposited by Chemical Vapor Deposition, AIP Conference Proceedings, 2034: 1-7

7. Konstantaki, Maria, et al. 2012. "An ethanol vapor detection probe based on a $\mathrm{ZnO}$ nanorod coated optical fiber long period grating. Optics express, 20(8): 8472-8484

8. Hassan N. and Hashim M. 2012. Catalyst-free growth of $\mathrm{ZnO}$ nanowires on $\mathrm{Si}$ (100) substrates: Effect of Substrate Position on Morphological, Structural and Optical Properties". ECS Journal Solid State Sciences Technology, 17(1): 86-89 .

9. Shaveta Th.,Sharma J.,and Sanjay K .2017. Effect of Silver Doping on Properties of ZnO nanoparticles by chemical Precipitation method". International Journal of Engineering Technology Science and Research, 4(12): 842-846.

10. Rabia Q. 2017. Effect of gamma radiation on morphological \& optical properties of $\mathrm{ZnO}$ nanopowder", Results in Physics, 7: 807-809.

11. Najiba A. , Ramla D. , Saba J. 2014. Effect of Gamma Irradiation on the Structural and Optical Properties of ZnO Thin Films", Journal of Computer Engineering, 16(1): 11-16.

12. Sahani R. M., Kumari C., Pandya A., and Dixit A. 2019. Efcient Alpha Radiation Detector using Low Temperature Hydrothermally Grown ZnO:Ga Nanorod Scintillator", Scientific Reports, 3(7): 1-9.

13. Chaudhary P. and Kumar V. 2019. Preparation of $\mathrm{ZnO}$ thin film using sol-gel dip- coating technique and their characterization for optoelectronic applications, WSN, 121: 64-71.

14. Nida K. 2019. Investigation of Optical and Morphological Properties of Co Doped $\mathrm{ZnO}$ Nanomaterials", Turkish Journal of Science and Technology, 14(1): 41-48.

15. Ghazwan Gh . Ali, Abdul Kahliq A.Sulamian, and Marwan Hafeedh Younus. 2019. Study of Porous Silicon Behavior via Neutron Irradiation: Fabrication and Characterization, Results in Physics, 14: 1-7.

16. Kasim U., Aisha Sh. and Alhaji Y. 2016. Optical and Structural characterization of low dose gamma irradiated Zinc Oxide $(\mathrm{ZnO})$ thin films prepared by Electrostatic spray pyrolysis , IOSR Journal of Applied Physics, 8(1): 1-8. 
17. Jamal R. K., Ali F. H., Hameed M. M., Aadim K. A. 2020. Designing A Zener Diode Using $\mathrm{Ag}_{2} \mathrm{O}(1-\mathrm{X}) \mathrm{ZnO}(\mathrm{X}) / \mathrm{PSi}$ Structures Deposited by Laser Induced Plasma Technique. Iraqi Journal of Science, 61(5): 1032-1039.

18. Safa K. Mustafa, Raied K. Jamal. 2019. Studying the Effect of Annealing on Optical and Structure Properties of $\mathrm{ZnO}$ Nanostructure Prepared by Laser Induced Plasma. Iraqi Journal of Science. 60 (10): 2168

19. Ziegler J., Biersack J., Littmark U. 2003. "The stopping and Range of Ions in Solids","SRIM", Pergamon Press, Oxford.

20. Bushra K . 2015. Effect of Gamma Ray Irradiation on Structural and Optical Properties of $\mathrm{ZnO}$ Thin Films, Ibn Al-Haitham J. for Pure \& Appl. Sci, 28(3): 7-17.

21. Ahmed M., Taghizadeh F., Auret F. 2019. The effect of alpha particle irradiation on electrical properties and defects of $\mathrm{ZnO}$ thin films prepared by sol-gel spin coating, Materials Science in Semiconductor Processing, 101: 82-86.

22. Nagarani N. 2013. Structural and optical characterization of $\mathrm{ZnO}$ thin films by Sol-Gel method. Journal on Photonics and Spintronics, 2(2): 2324-8572.

23. Znaidi T.,Touam T., and Vrel D. 2012. ZnO thin Films Synthesized by Sol-Gel Process for Photonic Applications. ACTA Physics Polonica A, 121(1): 165-173.

24. ABDALLAH B., ISMAIL A. 2019. Optical and structural study of low dose alpha irradiated zinc oxide (ZnO) thin film, Journal of Optoelectronics and Advanced Materials, 21(5): 401-406.

25. Muhammad R., Mukhlasur R., Farhad J. 2019. Structural, optical and photocatalysis properties of sol-gel deposited Al-doped ZnO thin films, Surfaces and Interfaces ,16: 120-126.

26. Khan Z., Khan M., Zulfequar M. , Khan M. 2011. Optical and structural properties of ZnO thin films Fabricated by sol-gel method. Mater Sci. Appl., 2(5): 340-349.

27. Hussain H ., Basil A. , Huda S. 2013. Nuclear radiation effect on $\mathrm{ZnO}$ performance, Journal of Basra Researches, 39(3): 72-81.

28. Sanaz A., Majid J., Morteza S. 2019. Preparation and characterization of gallium-doped zinc oxide/ polystyrene nanocomposite scintillator for alpha particles detection, Applied Physics A, 125(6): 450-462.

29. Sahani R., Chandni K., Arun P., Ambesh D. 2019. Efficient Alpha Radiation Detector using Low Temperature Hydrothermally Grown ZnO: Ga Nanorod Scintillator, Scientific Reports, 9(1) :1-9.

30. Shweikani R., Ismail A., and Jerby B. 2017. Preliminary study on the properties of Zinc Oxide( $\mathrm{ZnO})$ for alpha particles detection, International Journal of Radiation Research, 15(3): 301-306.

31. Rodica P. , Anca I. , Raluca G. 2015. Study of point defects in $\mathrm{ZnO}$ thin films irradiated with alpha particles, International Conference on Defects in Semiconductors, Espoo, Finland.

32. Shweikani, R., Ismail , A., and Jerby, B., 2017. Preliminary Study on the properties of Zinc Oxide ( $\mathrm{ZnO})$ for alpha particles detection, International Journal of Radiation Research,15(3): 301-306. 